\title{
História da cidade nas narrativas de jovens escolarizados: a relação entre consciência histórica e identidade
}

\author{
Geyso Dongley Germinari*
}

\section{Resumo}

O artigo aborda a relação entre a consciência histórica de jovens escolarizados que vivem em Curitiba-PR e a História da Cidade, tendo como fonte de análise narrativas históricas produzidas pelos jovens estudantes. A pesquisa segue a perspectiva da Educação Histórica, cujo foco direciona-se ao conhecimento sistemático das ideias históricas de alunos e professores, mobilizadas em situaçóes de aprendizagem. O fundamento principal dessa investigação é a teoria da história de Jörn Rüsen, particularmente o conceito de consciência histórica, que, segundo o teórico, articula o passado como experiência e o presente e o futuro como campos de açáo orientados pelo passado, e cujas funçóes essenciais são a orientação temporal e o estabelecimento de identidades individuais e coletivas. As inferências nas narrativas históricas indicaram uma forte influência de determinada ideia de identidade curitibana, identificada com a imagem da "cidade-modelo" de urbanização, na formação da consciência histórica de jovens escolarizados que vivem na cidade.

Palavras-chave: Jovem. Identidade. Ensino de História.

\footnotetext{
* Doutor em Educaçáo pela Universidade Federal do Paraná (UFPR). Professor do Programa de Mestrado e Doutorado em Educação da Universidade Tuiuti do Paraná (UTP). Pesquisador do Laboratório de Pesquisa em Educação Histórica (LAPEDUH).
} 


\section{Introdução}

Nos últimos anos, participei do projeto "Escola Universidade", uma parceria entre a Secretaria de Educaçâo do Município de Curitiba-PR e instituiçóes de Ensino Superior da regiấo com a finalidade de desenvolver projetos pedagógicos direcionados aos anos iniciais do Ensino Fundamental. Nessa ocasião, orientei professores de $3^{\circ}$ e $4^{\circ}$ anos na organização e aplicação de projetos de intervenção pedagógica na área de História.

A maior parte dos projetos tinha como proposta de intervenção o trabalho com a "identidade curitibana" numa perspectiva histórica, prioritariamente a partir do estudo do processo de imigração europeia para a regiáo no final do século XIX. O objetivo principal era desenvolver na criança, a partir do estudo da História local, um sentimento de pertencimento à cidade.

Na relação de orientação com as professoras responsáveis pela condução do projeto na escola, pude perceber que era forte a ideia da existência de uma "identidade curitibana" (entendida como um conjunto de características próprias dos habitantes de Curitiba), bem como a compreensão de que era importante desenvolver nas crianças esta dimensão identitária, a partir da seleção de determinados elementos do passado, em detrimento de outros.

A observação dessas ideias, no contexto dos anos iniciais do Ensino Fundamental, aliada ao contato com a tese de doutorado de Ferreira (2008) cujos resultados indicaram que, na década de 1990, o currículo e os materiais didáticos da Secretaria Municipal da Educação de Curitiba cumpriam a função de reforçar o projeto da cidade, matizado claramente pela intenção de consolidar a imagem da "cidade-modelo" de urbanização -, alimentaram as propostas da presente pesquisa. $\mathrm{O}$ diagnóstico da presença de determinadas ideias sobre a cidade de Curitiba nas escolas da rede pública municipal norteou a intenção de investigar a relação entre aprendizagem histórica e a ideia de Curitiba "cidade-modelo".

Nessa direção, privilegiei como sujeitos da investigação jovens do primeiro ano do Ensino Médio de escolas públicas de Curitiba que tivessem concluído o Ensino Fundamental no município de Curitiba, com o objetivo de avaliar possíveis relaçóes entre aprendizagem histórica e a ideia de Curitiba "cidade-modelo". Os jovens estudantes foram compreendidos a partir de suas determinaçóes sócio-históricas e a escola como um espaço de manifestação da experiência social desses jovens. 
Há alguns anos, tive a oportunidade de conhecer aqui no Brasil um debate sobre Educação Histórica cujo escopo resulta da comunicação entre professores brasileiros e professores de outros países, principalmente da Inglaterra e de Portugal. Um dos princípios constitutivos da Educação Histórica como campo de ação e investigação é de ordem teórica e diz respeito à relação intrínseca do ensinar História com o método e a filosofia da ciência histórica.

No doutorado, as minhas reflexôes sobre aprendizagem e ensino de História localizam-se no interior dos debates internacionais da Educação Histórica e nas pesquisas sobre a Didática da História desenvolvidas no Laboratório de Pesquisas em Educação Histórica, na Linha de Pesquisa Cultura, Escola e Ensino, do Programa de Pós-Graduação em Educação da Universidade Federal do Paraná. Tais investigações têm como foco compreender as ideias históricas de alunos e professores.

Procurei compreender como os jovens escolarizados que cursam o primeiro ano do Ensino Médio de escolas públicas possuem, em suas consciências históricas, elementos sobre a história de Curitiba, bem como explicitar a relação desses elementos com a formação das suas identidades de pertencimento à cidade.

O conceito de consciência histórica, segundo a teoria da História esboçada por Jörn Rüsen (2001), articula o passado como experiência e o presente e o futuro como campos de ação orientados pelo passado, cujas funçôes essenciais são a orientação temporal e a criação de identidade. A consciência histórica é a consciência humana que fornece sentido temporal à vida, pois relaciona num continuum temporal o passado, o presente e o futuro.

Esta proposta de investigaçáo se assenta na hipótese de que existe uma relaçáo entre consciência histórica dos jovens escolarizados, a ideia de Curitiba como "cidade- modelo" e a construçâo de uma determinada identidade de pertencimento à cidade.

A imagem de Curitiba como cidade ideal ganhou força nos anos 1970, especificamente nos períodos de 1971-1974, época da primeira gestáo do prefeito Jaime Lerner, e 1979-1983, correspondente ao seu segundo mandato. Nessa conjuntura, foi desenvolvido um amplo projeto de modernizaçáo urbana na cidade pautado no Plano Diretor de 1965 e nas diretrizes de planejamento estabelecidas pelo Instituto de Pesquisa e Planejamento Urbano de Curitiba (IPPUC). O processo de modernizaçáo teve continuidade nos anos 1990, 
quando o arquiteto Jaime Lerner assumiu pela terceira vez a Prefeitura da cidade.

Segundo seus idealizadores, a modernidade de Curitiba poderia ser percebida pela extensão da área verde $\left(50 \mathrm{~m}^{2}\right.$ por habitante), tráfego rápido, vias expressas para transporte coletivo, redes de ciclovias, áreas para pedestres no centro urbano, expansão e pluralidade de espaços de lazer e cultura.

Além das modificaçóes na infraestrutura urbana, que alteraram significativamente a paisagem do lugar nas últimas décadas, outro ponto fundamental do projeto foi a construção discursiva de uma nova imagem para cidade. A análise identifica na veiculaçáo da imagem da cidade um dos pontos centrais do projeto de modernização urbana de Curitiba (que contribuiu, nas últimas décadas, para a sedimentação de valores) e a construção de uma parte significativa da relação da população com a cidade. Essas ideias tiveram como referências principais os estudos de Fernanda Ester S. Garcia (1997); Dennison de Oliveira (2000); Nelson Rosário de Souza (2001); e Márcio de Oliveira (2001).

Nas últimas décadas do século $\mathrm{XX}$, algumas expressôes sintetizaram a imagem positiva da cidade, entre elas: Curitiba, laboratório de experiências urbanísticas; capital brasileira da qualidade de vida; cidade planejada, capital ecológica, capital de Primeiro Mundo.

Assim, o problema deste trabalho levanta a questão da relação entre consciência histórica de jovens, a ideia de Curitiba "cidade-modelo" e a identidade curitibana.

\section{Consciência histórica, narrativa e identidade}

A ideia de consciência histórica vem sendo discutida no âmbito da Filosofia da História. Segundo Dray (1964), este ramo da Filosofia tem como função esclarecer e analisar a "ideia" de História. A Filosofia da História, na atualidade, trata de problemas epistemológicos como o sentido da história e a constituição da consciência histórica.

Segundo Barca (2007, p. 116),

O conceito de consciência histórica, em debate no âmbito da filosofia analítica da História, constitui actualmente um dos objectos centrais de pesquisa no campo da 
educação histórica, com a intenção de reunir dados empíricos que possibilitem um melhor entendimento das ideias dos jovens acerca dos usos da História no seu quotidiano.

As contribuições de Rüsen (2001) para a discussão epistemológica sobre a relação da História com as tomadas de decisão na vida cotidiana têm permitido identificar alguns marcos da consciência histórica dos jovens (BARCA, 2007). Na perspectiva de Rüsen (2001), a consciência histórica é inerente à existência humana. Em outras palavras, é uma condição antropológica - portanto, culturalmente constituída - que não se restringe a um período da história, grupo social ou indivíduos aptos ao desenvolvimento intelectual da história.

O trabalho da consciência histórica é feito em atividades culturais específicas, que Rüsen (2006, p. 122) chama de "práticas de narração histórica". Schmidt e Garcia (2005) corroboram as apreensóes de Rüsen (2006). Para as autoras,

[...] a consciência histórica relaciona "ser" (identidade) e "dever" (ação) em uma narrativa significativa que toma os acontecimentos do passado com o objetivo de dar identidade aos sujeitos a partir de suas experiências individuais e coletivas e de tornar inteligível o seu presente, conferindo uma expectativa futura a essa atividade atual. Portanto, a consciência histórica tem uma "funçáo prática" de dar identidade aos sujeitos e fornecer à realidade em que eles vivem uma dimensão temporal, uma orientação que pode guiar a ação, intencionalmente, por meio da mediação da memória histórica. (SCHMIDT; GARCIA, 2005, p. 301).

Desse modo, a consciência histórica existe nas práticas de narração histórica. Dito de outra forma, a narrativa é a expressão material do pensamento histórico. Assim, por meio da narrativa chega-se à forma da consciência histórica constituída na mente dos homens. Essa prática cultural de interpretação do tempo é, de acordo com Rüsen (2001), antropologicamente universal.

Para Rüsen (2001, p. 60-61), a narrativa histórica refere-se a 
[...] um ato de fala, cuja universalidade antropológica náo pode ser contestada e com respeito à qual se pode demonstrar ser ela determinante da especificidade do pensamento histórico e, com isso, da peculiaridade do conhecimento histórico-científico [...] Em um ato de fala desse tipo, no qual se sintetizam, em uma unidade estrutural, as operaçóes mentais constitutivas da consciência histórica, no qual a consciência histórica se realiza, com efeito existe: a narrativa (histórica).

Ainda de acordo com Rüsen (2001, p. 149),

O pensamento histórico, em todas as suas formas e versóes, está condicionado por um determinado procedimento mental de o homem interpretar a si mesmo e a seu mundo: a narrativa de uma história. Narrar é uma prática cultural de interpretação do tempo, antropologicamente universal. A plenitude do passado cujo tornar-se presente se deve a uma atividade intelectual a que chamamos de "história" pode ser caracterizada, categoricamente, como narrativa. A "história" como passado tornado presente assume, por princípio, a forma de uma narrativa. O pensamento histórico obedece, pois, igualmente, a lógica da narrativa. Essa tese é tratada na teoria da história como o paradigma narrativista.

Contudo, Rüsen (2006) não nega a existência de elementos não narrativos operando no trabalho da consciência histórica em que a representação narrativa do passado apresente limites. Porém, o fenômeno cultural chamado História sustenta-se fundamentalmente na prática cultural da narrativa. Como ele afirma:

La forma lingüística dentro de la cual la consciencia histórica realiza su función de orientación es la de la narración. Desde esta visión, las operaciones por las cuales la mente humana realiza la síntesis histórica del tempo simultáneamente con las del valor y la experiencia se encuentran en la narración: el relato de una historia. (RÜSEN, 1992, p. 29). 
A narrativa histórica, como construção mental, difere de outros conteúdos da memória humana. Alguns aspectos caracterizam a narrativa histórica como elementos constitutivos do pensamento histórico geral e em particular do pensamento histórico científico.

No processo narrativo, alguns fatores são essenciais na formação da consciência histórica, os quais permitem diferenciar a narrativa histórica da multiplicidade de interpretaçóes da experiência do tempo que utilizam a narrativa como instrumento.

Em busca da especificidade da narrativa histórica como elemento de constituição de sentido sobre a experiência do tempo, uma questão geral é importante, ou seja, a tradicional distinção entre narrativa ficcional e não ficcional. Tal distinção origina-se de três especificaçôes da operação mental da narrativa na vida prática concreta.

A primeira especificidade a se destacar é que a narrativa histórica rememora um passado distante, que ultrapassa as lembranças individuais, vai além do tempo de uma vida individual. Essa expansão temporal é condição fundamental para conferir ao passado a qualidade de histórico. Além disso, a perspectiva de futuro, aberta pela consciência histórica, também ultrapassa o limite de uma vida individual. Como afirma Rüsen (2001, p. 63-64),

A lembrança flui natural e permanentemente no quadro de orientação da vida prática atual e preenche-o com interpretaçóes do tempo; ela é um componente essencial da orientação existencial do homem. A consciência histórica não é idêntica, contudo, à lembrança. Só se pode falar de consciência histórica quando, para interpretar experiências atuais do tempo, é necessário mobilizar a lembrança de determinada maneira: ela é transposta para o processo de tornar presente o passado mediante o movimento da narrativa. A mera subsistência do passado na memória ainda náo constitutiva da consciência histórica. Para a constituiçáo da consciência requer-se uma correlaçáo expressa do presente com o passado - ou seja, uma atividade intelectual que pode ser identificada e descrita como narrativa (histórica).

A segunda especificidade da narrativa histórica é que ela constitui a consciência histórica ao representar as mudanças temporais do passado, 
rememoradas no presente como processos contínuos. Nessa direção, as dimensôes temporais (passado, presente, futuro) ganham sentido, e assim o passado, como experiência, torna-se significativo para o presente e o futuro. Essa interdependência entre passado, presente e futuro é concebida como uma representação da continuidade. Tal representação dá unidade às três dimensões temporais.

Como destaca Rüsen (2006, p. 123),

Essa "razão histórica" é uma imagem, uma visão, um conceito ou uma idéia de tempo que mede as expectativas, os desejos, as esperanças, os medos e as ansiedades que ligam as mentes das pessoas nas suas atividades do dia-adia com a experiência do passado. O tempo real recordado sintetiza-se com o futuro projetado; passado e futuro emergem em uma imagem, visão ou conceito único da mudança e progresso temporal, que funciona como uma parte integral de orientação cultural no presente. Ciclos regulares e incessantes de ordem e desordem, a categoria de progresso, a crença de que Deus governa o mundo ou de que há uma ordem moral mundial (como o Tao) podem ser evocados como exemplos dessa idéia de tempo como uma ordem significativa das atividades humanas.

A prática cultural da narrativa histórica cria um sentido temporal para a vida humana, ou seja, cria um senso de que a vida pertence a uma dimensão temporal que inclui, numa única estrutura, o passado, presente e futuro.

Dentro da teoria da história de Rüsen (1992), a narrativa, como expressão da consciência histórica, é uma forma de constituição de sentido sobre o passado. Para este autor, a competência narrativa pode definir-se: "[...] como la habilidad de la conciencia humana para llevar a cabo procedimientos que dan sentido al pasado, haciendo efectiva una orientación temporal en la vida práctica presente por medio del recuerdo de la realidad pasada" (RÜSEN, 1992, p. 29).

A competência narrativa de "dar sentido ao passado" está relacionada à articulação de três qualidades do ato de narrar: experiência, interpretação e orientação.

A competência de experiência supóe uma habilidade para viver experiências temporais. Isso implica a capacidade de percepção da contingência 
e diferenças no tempo entre o passado, o presente e o futuro. A competência da interpretação da percepção das diferenças no tempo, mediante a articulação narrativa, se manifesta pela habilidade de aproximar as diferenças do tempo, por meio de uma concepção de um todo temporal, que abrange todas as dimensôes do tempo: passado, presente e futuro. Por fim, a competência de orientação se caracteriza pela capacidade de utilizar o todo temporal na orientação da vida prática contemporânea, conforme os modelos de interpretação das mudanças temporais.

A terceira especificidade da narrativa, como atividade intelectual fundamental na formação da consciência histórica, refere-se ao elemento que dá unidade interna às três dimensōes temporais, no processo de representação da continuidade, mediante a narrativa histórica. Trata-se da identidade daqueles que precisam produzir o sentido narrativo para poderem se orientar no tempo. A narrativa histórica está marcada pela intenção do narrador e seus destinatários (público) de não se perderem nas mudanças temporais de si e do mundo, mas de manterem a vida ordenada no fluxo do tempo. Segundo Rüsen (2001, p. 66),

Os homens têm de interpretar as mudanças temporais em que estão enredados a fim de continuarem seguros de si e de náo terem de recear perder-se nelas, ao se imiscuírem nelas pelo agir, o que precisam fazer, para poderem viver. A resistência dos homens à perda de si e seu esforço de auto-afirmação constituem-se como identidade mediante representaçốes de continuidade, com as quais relacionam as experiências do tempo com as intenções no tempo: a medida da plausibilidade e da consistência dessa relação, ou seja, o critério de sentido para a constituição de representaçôes abrangentes da continuidade é a permanência de si mesmos na evoluçáo do tempo.

A representaçáo de continuidade pode ser compreendida de quatro maneiras diferentes: tradicional, exemplar, crítica e genética. A tradicional caracteriza-se pela continuidade temporal como permanência de sistemas de vida originalmente constituídos e identidade pela afirmação de padróes culturais pré-conhecidos. A exemplar, pela continuidade temporal como a validade de regras que cobrem sistemas de vida temporalmente diferentes, e a formaçáo de identidade se dá pela generalização de experiências temporais como regras 
de conduta. A crítica, pela continuidade como alteração de dadas ideias de continuidade, e a identidade forma-se pela negação de determinados padróes conhecidos de autocompreensão. A genética caracteriza-se pela continuidade como um desenvolvimento, no qual os modos de vida mudam para estabelecer sua permanência dinamicamente, e a identidade constitui-se pela mediação da permanência e da mudança em um processo de autodefinição.

Nessa direção, segundo Rüsen (1992), a narrativa tem a função geral de orientar a vida prática no tempo, por meio da mobilização da memória da experiência temporal, desenvolvendo um conceito de continuidade e estabelecendo uma identidade.

O conceito de identidade ocupou extenso espaço na agenda de discussóes da teoria social nas últimas décadas do século XX. Os debates sobre identidade acontecem em torno de perspectivas teóricas variadas, no campo das Ciências Sociais e Humanas.

A ideia de identidade experimentou uma "inflação analítica". Para Martuccelli (2007), muitas vezes pela simples polissemia da palavra que desorienta. Outras vezes - o que, segundo este autor, pode ser questionado -, pela vontade de numerosos autores de fazer da identidade a perspectiva central do indivíduo.

Nas décadas de 1960 e 70, o tema tornou-se emergente, embalado pela descrença em princípios centrais que sustentavam a concepçáo de homem e mundo moderno. Em sentido amplo, a descrença recaiu sobre a compreensáo iluminista de homem e mundo, baseada em categorias como razáo, consciência, liberdade e progresso. No campo do conhecimento histórico,

[...] o projeto moderno, articulado pelo iluminismo, vê a historia como "espírito universal" - um centroconsciência-interioridade em avanço, um núcleo subjetivo e lógico que se exterioriza e retorna a si, integrando-se e concentrando-se progressivamente, tomando consciência de si. (REIS, 2006, p. 68).

A ontologia iluminista foi criticada de forma mais contundente a partir da década de 1960. Segundo Reis (2006, p. 45),

O século XX se deu historicamente conta dessa crise da Razão, já percebida e formulada por aqueles autores do 
século anterior, em meio às tragédias que acompanharam a derrota da Europa. O pensamento dessa derrota seria o "pós-moderno". A pós-modernidade desconstrói a metafísica humanista da sujetividade moderna deslegitima, deslembra, desmemoriza, quer esquecer o discurso da Razáo que levara ao totalitarismo, ao holocausto, às guerras mundiais.

A “crise da Razão" na perspectiva pós-moderna ${ }^{1}$ implicava também uma "crise de identidade", uma vez que a razão e a consciência, consideradas pontos centrais da concepção de homem iluminista-moderno, estavam sob julgamento.

A crítica à identidade moderna encontrava lastro no contexto de profundas transformaçóes das relaçóes sociais, caracterizadas pelo historiador britânico Eric Hobsbawm (1995) como uma verdadeira revolução cultural de padrōes mundiais. A melhor abordagem dessa revolução, para Hobsbawm, é por meio da família e do sexo, isto é, por meio da estrutura de relaçóes entre sexo e geraçôes.

$\mathrm{Na}$ maioria das sociedades, essas relaçóes resistiram às mudanças bruscas até a década de 1950. A vasta maioria da humanidade partilhava certas características, como a existência e a crença no casamento formal com relações sexuais privilegiadas entre os cônjuges; o adultério era universalmente tratado como crime; superioridade dos maridos em relação às esposas e dos pais em relação aos filhos (patriarcalismo), do mesmo modo com as gerações mais jovens; famílias com várias pessoas e nuclear, uma família com mais filhos.

Todavia, já na segunda metade do século XX esses arranjos sociais há muito existentes começaram a mudar com rapidez, sobretudo nos países ocidentais desenvolvidos, embora de forma desigual, mesmo dentro dessa região. $\mathrm{Na}$ maior parte do mundo, aumentaram os divórcios, os casais diminuíram o desejo de filhos, cresceram as relaçóes bissexuais, aumentou o número de pessoas vivendo sozinhas (isto é, não como um membro de um casal ou família maior), as famílias nucleares diminuíram, muitas mulheres passaram a chefiar a família e criar os filhos sozinhas. A interpretação desses fenômenos seguiu sob diferentes enfoques. Segundo Hobsbawm (1995, p. 332):

Uma vez que tais práticas e instituições não eram mais aceitas como parte do modo de ordenar a sociedade que ligava as pessoas umas às outras, e que assegurava a 
cooperação social e a reprodução, desapareceu a maior parte de sua capacidade de estruturar a vida social humana. Foram reduzidos simplesmente a manifestaçóes de preferências individuais e reivindicaçóes de que a lei reconhecesse a supremacia dessas preferências. Incerteza e imprevisibilidade eram eminentes. As agulhas das bússolas não tinham mais norte, os mapas tornaram-se inúteis. Isso foi o que se tornou cada vez mais evidente nos países de maior desenvolvimento a partir da década de 1960. Encontrou expressão ideológica numa variedade de teorias, do extremo liberalismo de mercado ao "pósmodernismo" e coisas que tais, que tentavam contornar inteiramente o problema de julgamento e valores, ou antes reduzi-lo ao único denominador da irrestrita liberdade do indivíduo.

O pensamento pós-moderno, destacado por Hobsbawm (1995), interpretou as mudanças das relaçóes sociais em curso na década de 1960 como o fim de um tempo baseado nos princípios modernos. Anunciaram a "morte do sujeito moderno" e proclamaram o nascimento de um "novo" sujeito, pós-moderno, pautado em novas dimensóes identitárias, em novas formas de reconhecimento.

Para Martuccelli (2007), a abordagem sociológica da condição moderna deve manter distância da ideia de uma crise contemporânea da identidade associada a uma fase de transformaçóes específicas das sociedades complexas cuja principal característica é a diversidade cultural, também denominada multiculturalismo.

Para este autor, a modernidade está condicionada pela crise de identidade. O conceito de modernidade, assim como o próprio processo que ele designa, revela uma tensão: um processo contínuo de construção e reconstrução da vida interna do homem ocidental que oscila entre a fragmentação e a universalidade das dimensões identitárias.

Assim sendo, para Martuccelli (2007), a chamada "crise de identidade", identificada com as transformaçóes sociais e culturais ocorridas na segunda metade do século XX, náo representa, de fato, uma novidade dentro do processo da modernidade. Nessa mesma perspectiva, Reis (2006) diz que a "crise pósmoderna”, localizada como um fenômeno social típico das décadas de 1960 e 
70, seria uma espécie de retorno aos primeiros dias da modernidade. "Essa crise pós-moderna ocorreu na Europa como desdobramento da revolução cultural moderna, européia, iniciada no século XVI" (REIS, 2006, p. 51).

$\mathrm{Na}$ perspectiva da sociologia da condição moderna delineada por Martuccelli, a identidade refere-se a dois grandes processos da vida humana. Por um lado, a identidade garante a continuidade dos indivíduos no tempo pela autocompreensão. Por outro lado, a identidade é o processo de vinculação da vida humana com elementos socioculturais.

Segundo Martuccelli (2007), a identidade emerge da complexa articulação entre uma história pessoal e de uma tradição social e cultural. Ela combina as propriedades comuns a um grupo de atores (exemplo: gênero, classe, raça, ideologia, tradiçóes familiares, locais e nacionais) e as propriedades mais individuais como a percepção, significado e atribuição de sentido ao mundo.

$\mathrm{O}$ enlace entre os aspectos individuais e coletivos na conformação da identidade ocorre por meio de um discurso coerente que o indivíduo faz de si mesmo. A identidade constitui-se quando o indivíduo desenvolve, por meio da narrativa, uma abordagem coerente e unitária de si. Ao narrar a sua vida, o indivíduo inventa-se e institui seu pertencimento no mundo. Nesse processo, lança mão de diferentes tópicos narrativos de si mesmo, aos quais pode recorrer para falar de suas vivências e práticas. Pela narrativa, o indivíduo busca manter uma personalidade coerente com a sua trajetória de vida, mas também uma continuidade da experiência ao criar uma continuidade entre diferentes fases da vida.

Entendo, a partir da sociologia da condição moderna, que as identidades se formam pelo trabalho permanente de estruturar a vida no tempo, mediante a elaboração de narrativas coerentes e unitárias de si mesmo. Desta forma, a noção de identidade esboçada por Martuccelli (2007) aproxima-se da noção de consciência histórica desenhada por Rüsen (2001) no âmbito da Filosofia da História.

Tanto Martuccelli (2007) quanto Rüsen (2001) advogam que a identidade é uma dimensão essencial para que os homens não se percam nas transformaçôes do mundo e de si mesmos. Pela identidade, seja ela histórica ou não, torna-se possível para os seres humanos estabelecerem uma autocompreensáo coerente e unitária da vida, diante das mudanças sofridas no mundo. Outro ponto de convergência entre os autores é que a identidade se institui pela prática da narrativa. 
Martuccelli (2007, p. 307) coloca a questão nos seguintes termos:

La identidad es un espacio donde el individuo se forja, por el relato, un sentimiento de continuidad a través del tiempo e incluso, a veces, un sentimiento de coherencia interna que le permite tomarse narrativamente como un individuo singular, pero siempre con la ayuda de elementos sociales y culturales.

Rüsen (2001) aborda a relação consciência histórica, narrativa, representaçáo da continuidade e identidade da seguinte forma:

[...] a consciência histórica constitui-se mediante a operação, genérica e elementar da vida prática, do narrar, com a qual os homens orientam seu agir e sofrer no tempo. Mediante a narrativa histórica são formuladas representaçóes da continuidade da evolução temporal dos homens e de seu mundo, instituidoras, por meio da memória, e inseridas, como determinação de sentido, no quadro de orientação da vida prática humana. (RÜSEN, 2001, p. 66-67)

Por meio da consciência histórica, as identidades ganham uma dimensão temporal que toma a forma de identidade histórica na história. Esse processo pode ser caracterizado como a transformação de identidades individuais e coletivas, constituídas ao longo da vida, em identidades históricas. Dito de outra forma, as identidades constituídas cotidianamente - a partir da conexão de diferentes registros individuais e coletivos - ganham uma extensão temporal de longa duração. Nesse movimento, há um ganho de tempo. Nas palavras de Rüsen (2001, p. 60), "a consciência histórica é, pois, guiada pela intenção de dominar o tempo que é experimentado como ameaça de perderse na transformação do mundo e dele mesmo, o pensamento histórico é, por conseguinte, ganho de tempo, o conhecimento histórico é o tempo ganho".

A aproximação teórica entre Martuccelli (2007) e Rüsen (2001) permite dizer que a constituiçẫo das identidades mediante a narrativa da própria vida é uma prática antropológica de autocompreensão da vida no curso do tempo. 
Assim, os seres humanos criam suas identidades por meio do exercício narrativo de identificar a vida no fluxo do tempo.

Para Martuccelli (2007), as narrativas que instituem as identidades são aquelas que criam um sentimento de continuidade do individuo através do tempo. Nessa mesma direção, Rüsen afirma que a narrativa constitui a identidade histórica por meio de representaçōes da continuidade da evolução temporal dos homens e de seu mundo. O conceito de identidade, neste autor, designa o processo de identificar a vida dentro de um continnum temporal, numa relação intrínseca entre o passado, o presente e o futuro. Portanto, a partir desses autores, a identidade pode ser considerada como o lugar onde o indivíduo se forja pela narrativa ao criar um sentido interno de continuidade da vida no tempo. Esse tipo de sentido permite aos homens estabelecerem relaçóes coerentes entre suas dimensões individuais e as estruturas sócio-históricas objetivas, considerando, a partir dos pressupostos teóricos de Rüsen, que a operação mental realizada pela consciência histórica ao articular o passado como experiência e o presente e o futuro como campos de ação orientados pelo passado é uma necessidade universal. As formas de produzir essa liga são diferentes, conforme as identidades específicas de cada indivíduo ou grupo.

A identidade, também segundo Martuccelli (2007), constitui-se por meio de um discurso coerente que o indivíduo faz de si mesmo. Por meio da narrativa, o indivíduo pode desenvolver uma abordagem coerente e unitária de si. Esse processo exige a consciência de sua própria historicidade, portanto, uma determinada consciência histórica.

Apesar de o indivíduo criar as suas identidades pela narrativa, não o faz de qualquer forma, uma vez que ele não está separado das pressóes situacionais e das definiçóes impostas e herdadas da realidade social. De acordo com Martuccelli (2007), diferentes manifestaçóes identitárias podem fazer o uso de tópicos narrativos diferentes (matizados por referências científicas, mediáticas e lugares comuns). Os tópicos são estruturados socialmente e emergem de tradiçóes culturais, atados sempre a um contexto histórico e social.

Para esse mesmo autor, a identidade existe em função das posiçóes sociais, podendo haver uma superestruturação "transversal" dos tópicos narrativos. Isso não quer dizer que os indivíduos sejam "modelos" socialmente elaborados. Todavia, é preciso perceber que há sempre uma correspondência entre as narrativas usadas pelo ator e sua posição social. 
A identidade pode ser considerada o lugar onde o indivíduo se forja pela narrativa ao criar um sentimento de continuidade no tempo e um sentimento de coerência interna, que lhe permite se interpretar narrativamente como sendo um indivíduo singular, porém, matizado por elementos sociais e culturais. Por meio da identidade, o indivíduo se afirma como uma variante particular de um modelo geral, servindo-se de elementos de uma tradiçáo cultural. Nesta direçẫo, entende-se que as identidades não preexistem à sua construção, uma vez que resultam de construções sociais e históricas variadas. Elas são frutos de uma coexistência de diferentes tradiçóes, pois toda identidade pressupóe estruturas históricas precedentes.

A partir desses pressupostos teóricos, compreende-se que a relação entre identidade e a consciência histórica dos jovens curitibanos depende do seu contexto social e cultural. Nessa direção, procura-se entender o jovem como um sujeito sócio-histórico que vive a sua condiçáo juvenil (o modo como a sociedade moderna constitui e significa a juventude como uma idade da vida), a partir de uma pluralidade de identidades, as quais revelam as diferentes trajetórias que os jovens escolarizados experimentam com base nos mais diversos contornos, como os de classe, gênero, etnia, sexualidade, nacionalidade.

\section{Análise de narrativas históricas de jovens escolarizados}

O arcabouço teórico construído orientou o percurso da investigação empírica de natureza qualitativa e interpretativa. Essa fase da pesquisa foi organizada em três etapas, respectivamente desenvolvida como estudo exploratório, piloto e principal. A técnica de coleta de dados consistiu na aplicação de um questionário semiestruturado em cada etapa. Esse encaminhamento metodológico possibilitou um maior controle dos dados coletados. No total, o trabalho de campo envolveu 174 jovens de cinco escolas da rede pública estadual do Paraná, localizadas na região sul de Curitiba. O material empírico coletado possibilitou fazer algumas análises em relação às identidades dos jovens sobre a cidade de Curitiba e a relação com a formação da consciência histórica.

Neste artigo, apresento os resultados do estudo piloto, o qual foi desenvolvido em uma escola pública estadual localizada na regiáo sul de Curitiba. No momento da pesquisa, a escola contava com 650 alunos matriculados nos Ensinos Fundamental e Médio. A coleta de dados foi realizada com 33 jovens 
de uma turma do 1ํo ano do Ensino Médio. A atividade ocorreu no final do turno da manhã.

Quanto ao gênero, o grupo pesquisado apresentou distribuição equilibrada (17 homens e 16 mulheres). A faixa etária concentrou-se entre 14 e 16 anos; 28 dos 33 jovens tinham entre 14 e 16 anos, e a grande maioria possuía 14 anos, idade compatível com série estudada, 1ำ ano do Ensino Médio.

Os dados da formação acadêmica dos pais e mães indicaram uma alta concentração na formação fundamental e média (27 pais de 32 jovens e 31 mães de 33 jovens). Não se pode afirmar, neste momento, que a formação dos pais e mães exerceu influência na natureza das respostas dadas pelos jovens. A maior parte dos jovens não trabalha, apenas oito responderam que trabalham, dois disseram que trabalham com a família, e um trabalha no comércio.

Os jovens foram informados pelo professor sobre o objetivo da pesquisa, e eu expliquei o modo de preenchimento de cada questáo. Em seguida, o questionário foi distribuído. A atividade durou 50 (cinquenta) minutos. Eu e o professor permanecemos na sala durante todo o tempo de aplicação.

Em uma das questôes, procurei conhecer a relação entre a consciência histórica dos jovens e a sua identidade em relação à cidade, utilizando para isso as narrativas históricas sobre a cidade de Curitiba a partir da seguinte pergunta: "Escreva uma carta para um amigo que mora em outra cidade contando sobre os últimos 50 anos da história de Curitiba".

Dos 33 jovens participantes do estudo piloto, 23 produziram a narrativa solicitada e dez apresentaram textos fragmentados e sem sentido, o que impossibilitou a análise.

As narrativas elaboradas pelos jovens no estudo piloto foram categorizadas a partir do conceito de tópicos narrativos. Conforme Martuccelli (2007), todo sentimento de pertencimento (identidade) constitui-se mediante a narrativa de si mesmo. Por meio dessa prática, o indivíduo cria múltiplas dimensões identitárias para sua vida, as quais se estruturam pelo uso de diferentes tópicos narrativos, que emergem de tradiçôes culturais. No estudo piloto, verifiquei a presença de determinados tópicos narrativos.

O tópico narrativo lugar refere-se a determinados locais da cidade, como parques, shoppings e pontos turísticos. No total, nove jovens utilizaram esse tópico para estruturar suas narrativas. Carol, de 14 anos, organizou a sua narrativa da seguinte forma: 
Amigo. Escrevendo para lhe contar que Curitiba nos últimos 50 anos tem nos surpreendido com seus parques, suas belezas. Tem surpreendido com a qualidade que nos trás.

Curitiba começou como todas as outras cidades, pobrezinha quase sem nada. Mas, agora graças a nós e os colaboradores nossa Curitiba hoje é conhecida como uma das melhores cidades para se viver na América Latina.

Amigo se eu fosse você mudaria para cá !!! Atenciosamente Carol.

O segundo tópico mais usado foi urbanizaçáo. Ao todo, seis jovens expressaram em suas narrativas questóes relacionadas com o trânsito, pavimentação de ruas e transporte coletivo. Tais aspectos apareceram na narrativa de Jéssica, de 14 anos:

Querida Amiga

Onde moro (Curitiba) ocorreram muitas mudanças de 50 anos pra cá. A linha verde com várias pistas facilitando a articulação do trânsito. O transporte (ônibus) hoje é mais sofisticado, contando com os biarticulados.

Enfim são muitas mudanças, mas devo lhe dizer que hoje Curitiba é uma cidade muito bem situada e felizmente contando com o maior salário do Brasil.

O tópico narrativo tecnologia usado por quatro jovens destaca a evolução tecnológica pela qual a cidade passou nos últimos 50 anos. Joaquim, de 16 anos, destacou esses avanços em sua narrativa:

Meu caro amigo, venho por meio desta, dizer sobre a história de Curitiba.

Durante 50 anos houve muitas mudanças, como por exemplo: as roupas, estilos de música, tecnologia avançada como: mp7, mp3, computadores, carros, muitos coisas boas; tem os seus defeitos, mas é muito bom.

Aqui esta um pouco da história da minha cidade. (Joaquim, 16 anos).

Dos 23 jovens que produziram as narrativas, três expressaram preocupação com a violência. Essas narrativas foram categorizadas como tópico narrativo 
violência. Na perspectiva dos jovens, a cidade, apesar de boa para viver e morar, poderia melhorar na área de segurança pública. De acordo com Camila, de 14 anos:

A vida em Curitiba tem sido maravilhosa nos últimos 50 anos.

Possuímos parques lindos ótimos para passeios. Confesso que a segurança ainda pode melhorar mesmo sendo uma cidade mais segura que as outras ainda pode melhorar. Quando possuir um tempo livre venha conhecer minha cidade, nấo irá se arrepender.

Abraços.

A categoria tópico narrativo política foi a menos utilizada pelos jovens. Apenas Arthur, de 14 anos, estruturou sua narrativa histórica sobre os últimos 50 anos de Curitiba em torno da ação dos políticos, como se pode depreender do seu texto:

Aqui em Curitiba temos progredido muito, graças aos governantes daqui. Eles têm feito muita coisa para melhorar a cidade e estão conseguindo. $s$ possível venha passar uns tempos aqui para ver você mesmo o que lhe disse.

Um abraço

A categorização das narrativas históricas - expressão material da consciência histórica (RÜSEN, 2001) - a partir do conceito de tópicos narrativos permitiu verificar o modo como as identidades dos jovens escolarizados acerca da cidade de Curitiba se expressam em sua consciência histórica.

Partindo desses dados, é possível inferir que a relação da maioria dos jovens com determinados lugares da cidade, aspecto que revela suas identidades acerca da cidade, orienta, em certa medida, a estruturação de suas narrativas históricas sobre os últimos 50 anos da cidade de Curitiba, visto que, na questão 4, a maioria dos jovens mobilizou o tópico narrativo lugar. Portanto, evidencia-se que há uma intrínseca relação entre a experiência dos jovens na cidade e a formação de sua consciência histórica sobre a cidade.

Além dos tópicos narrativos mapeados, procurei verificar como os jovens representam a ideia de continuidade entre o passado, o presente e o futuro. À luz da teoria de Rüsen (2001) e Martuccelli (2007), compreende-se que a 
identidade é o espaço no qual o indivíduo se inventa pela narrativa, ao criar representações de continuidade temporal que o orientam diante da mudança no tempo.

Todos os jovens ofereceram uma narrativa histórica estruturada em torno da ideia de progresso. Tal ideia foi mobilizada independentemente do tópico narrativo utilizado. Este sentido histórico aparece na narrativa de Denise, de 15 anos:

Nos últimos anos, foram feitas novas obras em Curitiba, que favoreceram muito os moradores. Muitas pessoas tiveram oportunidades de mudar de vida.

Foram feitas novas estradas, casas, escolas, creches, praças, clubes, edifícios comerciais, e outros que já existiam foram reformados. O transporte também melhorou muito, foram feitos novos ônibus para deixar cada vez melhor o transporte coletivo a quem precisa.

Cada vez mais a sociedade melhora, com tudo isso que aconteceu, está acontecendo e ainda vai acontecer, Curitiba vai crescer muito, e ainda terá chance de se tornar uma cidade modelo.

Lúcia, de 16 anos, narrou a história de Curitiba assim:

Oi querido!

Estou the enviando uma carta para contar as novidades. Vou contar um pouco da minha cidade Curitiba, seus últimos 50 anos, minha cidade está bem localizada, porém, bem atualizada de uns anos para cá, mudou muita coisa, mudou para melhor na época era tudo mais tipo lembrança do surgimento de Curitiba.

Hoje aqui está tudo muito novo, mais cara de urbanização mesmo: como shopping, parques, ruas, tudo mais cara de Curitiba. É sim uma cidade grande, com muitos habitantes.

Essa é minha cidade Benhê.

Beijo me liga.

O resultado das narrativas produzidas pelos jovens dessa amostragem converge em direção à assertiva de que elas são narrativas matizadas pela 
percepção das experiências que os jovens têm da cidade, estruturadas na forte influência do discurso oficial, que coloca Curitiba como uma "cidade-modelo" em urbanização.

A análise dos resultados desse estudo indicou algumas consideraçóes iniciais, em relação à identidade dos jovens, consciência histórica e a ideia de "cidade-modelo":

" há uma presença, nas identidades dos jovens em relação à cidade, de elementos associados à ideia de Curitiba "cidade-modelo";

" nas narrativas históricas, a ideia de uma identidade curitibana construída pelo discurso de Curitiba "cidade-modelo" aparece associada às questóes de infraestrutura urbana.

De modo geral, os dados levantados indicam que a vida dos jovens investigados em Curitiba é marcada por uma forte tensão. De um lado, os jovens têm uma visão positiva da cidade. A maior parte desses jovens gosta de praticamente tudo que a cidade oferece: parques, áreas verdes, transporte coletivo, planejamento urbano e espaços de lazer. Esse ponto de vista reforça a ideia de "Curitiba, cidade modelo de urbanizaçáo", conceito criado pela administração pública a partir da década de 1970. Porém, de outro lado, em menor número, os jovens enxergam uma cidade com os mesmos problemas sociais sofridos pelas demais cidades brasileiras, como a violência e a pobreza. Esse diagnóstico se aproxima das conclusóes da investigação de Sallas (1999) desenvolvida com jovens curitibanos no final da década de 1990. Segundo a pesquisadora,

Os jovens visualizam mais fortemente a cidade lazer $-o$ espaço do lúdico, que oferece entretenimento e áreas verdes - que a cidade fria, que afasta e oprime os não curitibanos. É a cidade que amam, embora não a isentem de críticas. Visualizam predominantemente seus aspectos positivos, como espaço de sua sociabilidade, mas com problemas sociais. Percebem que vivem um momento crítico, quando a cidade começa perder sua "qualidade de vida", seu diferencial positivo quando comparada a outras e matriz do "orgulho de ser curitibano". (SALLAS, 1999, p. 86).

A análise aponta para uma forte proximidade entre o tipo de passado 
apreendido pelos jovens na Escola Fundamental com o passado contado pela administração pública via propaganda, como estratégia política de consolidar um determinado projeto de cidade, identificado com o discurso da cidademodelo. A relaçáo pode ser mais bem percebida quando os jovens acessam prioritariamente um passado da cidade formado pela presença do imigrante europeu. Como afirma Oliveira (2000), fazia parte do projeto de modernização urbana de Curitiba, desde a década de 1970, a associação entre o progresso da cidade e a imigração europeia. A valorização de determinadas etnias contribuiu na construção da imagem da cidade europeia, organizada e de Primeiro Mundo.

Além desse aspecto, na década de 1990, de acordo com a tese de doutorado de Ferreira (2008), havia uma intrínseca relação entre o projeto oficial de cidade e a proposta curricular da rede municipal de ensino. Conforme a autora, ao analisar o currículo oficial da rede municipal de Curitiba, constatou que o documento cumpriu uma função muito mais de reforçar as ideias e supostas verdades sobre a cidade, tais como "cidade europeia", "um outro Brasil", "cidademodelo", de "planejamento urbano exemplar" do que questionar a cidade e o modo de vida do curitibano.

Além do currículo, Ferreira (2008) analisou a coleção de livros didáticos "Liçóes Curitibanas", distribuída aos alunos da rede municipal no governo do prefeito Rafael Greca (1993-1996), e detectou a clara intenção do material de ensinar às crianças uma determinada Curitiba, idealizada, branca e exemplar. A autora destacou que alguns conteúdos tinham a intenção de promover a relação entre a história curitibana e o projeto de cidade evidenciado na década de 1990. Nessa direção, "[...] os atores sociais que pensaram o projeto da cidade, na década de 1990, e mesmo, muitas décadas antes, operaram de sorte a resgatar, produzir ou mesmo forjar uma história” (FERREIRA, 2008, p. 46). Esses atores selecionaram o passado que interessava, enfatizando alguns aspectos históricos, como a fundação da cidade, o ascendente progresso nos século XVII e XVIII, e a contribuição do imigrante europeu na formação cultural curitibana, em detrimento de outros, como o conflito entre colonizadores e indígenas no século XVI, a pobreza nos séculos XVII e XVIII, e a presença do negro na formação social da cidade. A seleção do passado feita a serviço do projeto modernizador da cidade ainda rende seus frutos, visto que os jovens desta investigação consideram a imagem da "cidade-modelo" como representativa da cidade. 


\section{Considerações finais}

Compreender a forma como a identidade de jovens escolarizados que vivem em Curitiba expressa sua consciência histórica em relação à cidade foi o meu principal questionamento acadêmico como professor/pesquisador dessa importante temática da educação histórica que é a consciência histórica dos sujeitos no universo da escola. Meus estudos, no doutorado, me levaram a perceber a necessidade de desenvolver pesquisas sobre a relação dos alunos com a história local.

E foi em Rüsen (2001), a partir do quadro conceitual que ele propóe objetivando orientar as pesquisas sobre consciência histórica de jovens, que encontrei embasamento para aprofundar a análise da relação entre consciência histórica e identidade. As contribuições para a discussão epistemológica acerca das relações da história com a vida prática têm possibilitado identificar alguns caminhos de análise da consciência histórica de jovens. De acordo com Rüsen (2001), por seu papel em nos orientar no tempo, a consciência história tem duas funções essenciais: orientação temporal da vida prática externa e interna.

A competência interna de orientar a vida prática denomina-se identidade histórica. A identidade histórica fornece à vida um sentido temporal de continuidade entre o passado, o presente e o futuro. Esse trabalho da consciência histórica se realiza nas práticas de narração histórica. Ademais, Rüsen (2001) afirma que o arranjo das três dimensôes temporais (passado, presente, futuro), pela narrativa histórica, assume formas diferentes conforme o quadro de referências de orientação cultural da existência humana, que incluem diferentes dimensôes identitárias construídas ao longo da vida.

Tais compreensóes exigiram a busca de um conceito de identidade adequado à concepção de consciência histórica de Rüsen (2001). Essa tarefa trouxe um desafio à investigação, uma vez que o conceito de identidade tem sido tratado com maior intensidade pelas perspectivas pós-modernas que, de maneira geral, negam a existência de ordem temporal compreensiva de tempo, incluindo passado, presente e futuro em uma mesma estrutura.

A partir da aproximação teórica de Rüsen (2001) e Martuccelli (2007), concluí que as identidades históricas e outras identidades, especialmente as geracionais, constituídas ao longo da vida cumprem a função de suprir as carências humanas de orientaçáo no fluxo do tempo. A identidade orienta as pessoas diante da ideia de mudança temporal, de modo que possam permanecer 
em suas mudanças de vida sem deixarem de ser elas mesmas. Diante disso, é possível afirmar que a consciência histórica reestrutura as identidades pelo redimensionamento temporal, ou seja, pelo trabalho de ressignificação histórica das identidades. Nesse processo, as dimensôes temporais das identidades se ampliam para muito além do tempo de duração de uma vida pessoal. A compreensão de que existe uma relação entre consciência histórica e identidade sustenta a consideração de que as identidades construídas pelos jovens escolarizados sobre a cidade de Curitiba, no presente, se expressam de alguma maneira em sua consciência histórica.

A partir dessa inferência, busquei entender a relação entre a ideia de Curitiba "cidade-modelo" e a formação da consciência histórica dos jovens escolarizados. Quando penso na relação entre consciência histórica e identidade, me reporto a Schmidt (2002, p. 201)2 , que afirma que,

[...] no caso específico dos jovens brasileiros, residentes na cidade de Curitiba, Estado do Paraná, o envolvimento afetivo com a cidade não pode ser desconsiderado na medida em que há um forte marketing político em torno da valorização de Curitiba como cidade ideal, de primeiro mundo.

Deste modo, procurei compreender, com base em estudos sociológicos e historiográficos, o processo de construção de uma determinada imagem da cidade de Curitiba, vinculada à ideia de "cidade-modelo" de urbanizaçâo, entre as décadas de 1970 e 1990.

No tocante à relação dos jovens escolarizados com a cidade de Curitiba, constatei a existência de identidades individuais matizadas por elementos subjetivos e identidades coletivas que tomam como referência elementos sociais para definir o pertencimento à cidade.

A identidade coletiva manifesta-se em dois sentidos: por um lado, a maior parte dos jovens tem uma visão positiva da cidade: valorizam os parques, as áreas verdes, o transporte coletivo, o planejamento urbano e os espaços de lazer, ponto de vista fortemente marcado pela ideia de Curitiba "cidade-modelo" de urbanização, criada pela administração pública a partir da década de 1970. De outro lado, em menor escala, os jovens percebem uma cidade com problemas sociais, semelhantes aos sofridos por outras cidades, como a violência. Nessa direção, verifiquei que há, entre os jovens pesquisados, uma identidade coletiva 
fortemente matizada pelas ideias e valores difundidos pelos discursos que edificaram a "cidade-modelo", ou seja, essa imagem, entre os jovens, é mais forte que uma eventual problematização da vida na cidade.

A respeito da relação das ideias dos jovens escolarizados sobre a cidade e a formação da sua consciência histórica, constatei, por meio da análise das narrativas históricas, a forte presença da identidade coletiva associada às ideias que consolidaram a imagem da "cidade-modelo". A presença dessas ideias na consciência histórica dos jovens tomou a forma de tópicos narrativos sobre lugares simbólicos e infraestrutura urbana.

Os resultados da investigação convergem em direção à tese de que há uma tensão entre a consciência histórica e as identidades dos jovens escolarizados acerca do pertencimento à cidade. Partindo do pressuposto de que o passado é recordado de diferentes maneiras conforme os quadros de referência cultural, posso afirmar que o passado de Curitiba é rememorado pelos jovens de acordo com suas ideias de pertencimento à cidade. Por sua vez, essas ideias comportam diferentes registros individuais e coletivos, predominantemente matizados pela relação com um passado prático construído a partir da ideia de Curitiba "cidade-modelo".

Nesse sentido, por meio da narrativa (expressão da consciência histórica) sobre o passado de Curitiba, as identidades acerca da cidade são reveladas possibilitando compreender o tipo de relação que os jovens estabelecem com o passado, presente e futuro. Esta narração varia de acordo com a forma como eles articulam o passado como experiência e o presente e o futuro como campos de ação orientados pela interpretação deste passado (RÜSEN, 2001).

Considerando que a experiência dos jovens no presente é marcada pela tensão entre a consciência histórica e as identidades de pertencimento à cidade, a sua ida ao passado da cidade está marcada pela ideia de uma história construída em funçáo de consolidar um determinado projeto de cidade, identificada com o discurso de "cidade-modelo".

\section{Notas}

$1 \mathrm{Na}$ atualidade, o pós-modernismo aparece como um movimento multifacetado em suas ideias e projetos.

2 Consideração apresentada no artigo: "Jovens brasileiros e europeus: identidade, cultura e ensino de história” (SCHMIDT, 2002). Este 
trabalho apresentou os resultados parciais da pesquisa "Construindo conhecimentos, produzindo práticas, pesquisando o cotidiano escolar", desenvolvida por pesquisadores da Universidade Federal do Paraná, com a participação de alunos da Escola Média da cidade de Curitiba-PR entre os anos de 1998-2000. Cinco professores e 21 alunos foram observados e entrevistados.

\section{REFERÊNCIAS}

BARCA, Isabel. Marcos de consciência histórica de jovens portugueses. Currículo sem fronteiras, [S. 1.], v. 7, n. 1, p. 115-126, jan./jun. 2007. Disponível em: <http://www.curriculosemfronteiras.org/vol7iss1articles/ barca.pdf>. Acesso em: 15 jun. 2009.

DRAY, William. Filosofia da História. Rio de janeiro: Ler, 1964.

FERREIRA, Valéria M. R. Tecendo uma cidade modelar: relaçóes entre currículo, educaçáo escolar e projeto da cidade de Curitiba na década de 1990. 2008. 261 f. Tese (Doutorado em Educação) - Programa de Estudos Pós-Graduados em Educação: História, Política, Sociedade, Pontifícia Universidade Católica de São Paulo, São Paulo, 2008.

GARCIA, Fernanda Esther Sánchez. Cidade espetáculo: política, planejamento e city marketing. Curitiba: Palavra, 1997. 166 p.

HOBSBAWM, Eric J. Revolução Cultural. In: HOBSBAWM, Eric J. Era dos Extremos: o breve século XX, 1914-1991. São Paulo: Companhia das Letras, 1995. p. 314-336.

MARTUCCELLI, Danilo. Gramáticas del individuo. Buenos Aires: Losada, 2007. $500 \mathrm{p}$.

OLIVEIRA, Dennison de. Curitiba e o mito da cidade-modelo. Curitiba: Ed. da UFPR, 2000. 203 p.

OLIVEIRA, Márcio de. A trajetória do discurso ambiental em Curitiba (1960-2000). Revista de Sociologia Política. Curitiba, v. 16, p. 97-106, jun. 2001.

REIS, José Carlos. História e teoria. Rio de Janeiro: FGV, 2006. 246 p. 
RÜSEN, Jörn. El desarrollo de la competencia narrativa en el aprendizaje histórico: una hipótesis ontogenética relativa a la conciencia moral. Tradução de Silvia Finocchio. Propuesta Educativa. Buenos Aires, n. 7, p. 27-36, 1992.

RÜSEN, Jörn. Razão histórica: teoria da história, fundamentos da ciência histórica. Brasília: Editora da Universidade de Brasília, 2001.194 p.

RÜSEN, Jörn. Historiografia comparativa intercultural. In: MALERBA, Jurandir. (Org.). A História Escrita: teoria e história da historiografia. São Paulo: Contexto, 2006. 238 p.

SALLAS, Ana Luisa Fayet (Coord.). Os jovens de Curitiba: esperanças e desencantos: juventude, violência e cidadania. Brasília: Unesco, 1999.

SCHMIDT, Maria Auxiliadora. Jovens brasileiros e europeus: identidade, cultura e ensino de história (1998-2000). Revista Perspectiva. Florianópolis, v. 20, n. Especial, 183-208, jul./dez. 2002.

SCHMIDT, Maria Auxiliadora; GARCIA, Tânia Maria F. Braga. A formação da consciência histórica de alunos e professores e o cotidiano em aulas de história. Cad. Cedes, Campinas, SP, v. 25, n. 67, p. 297-308, set./dez. 2005.

SOUZA, Nelson Rosário de. Planejamento urbano em Curitiba: saber técnico, classificação dos citadinos e partilha da cidade. Revista Sociologia Politica, Curitiba, v. 16, p. 107-122, jun. 2001. 
Historia de la ciudad en las narraciones de los estudiantes de enseñanza media: una relación entre conciencia histórica e identidad

\section{Resumen}

El artículo analiza la relación entre la conciencia histórica de jóvenes de Enseñanza Media viven en Curitiba-PR y la historia de la ciudad, teniendo como fuente de análisis, narrativas históricas producidas por los jóvenes estudiantes. La pesquisa sigue la perspectiva de la Educación Histórica, cuyo enfoque se dirige hacia el conocimiento sistemático de las ideas históricas de estudiantes y profesores, movilizados en situaciones de aprendizaje. El fundamento principal de esta investigación es la teoría de la historia de Jörn Rüsen, particularmente el concepto de conciencia histórica, que, según el teórico, articula el pasado como experiencia el presente y el futuro como campos de acción orientados por el pasado, y cuyas funciones esenciales son la orientación temporal y el establecimiento de identidades individuales y colectivas. Las inferencias en las narrativas históricas indicaron una fuerte influencia de una determinada idea de identidad curitibana (identificada con la imagen de la "ciudad-modelo" de urbanización) en la formación de la conciencia histórica de los estudiantes de Enseñanza Media que viven en la ciudad.

Palabras claves: Joven. Identidad. Enseñanza de la Historia.
History of the city in the narrative of school youths: the relation between historic awareness and identity

\section{Abstract}

This article addresses the relationship between the historic awareness of students in Curitiba, Parana State and the history of the city, using as a source historical narratives produced by young students. The research takes a historical-education perspective, which focuses on developing a systematic knowledge of the historic ideas of students' and teachers' that were generated during a learning process. The main foundation of the study is Jörn Rüsen's theory of history, especially the concept of historical awareness, which he affirms articulates the past as experience and the present and future as fields of action guided by the past, and whose essential functions are temporal orientation and the establishment of individual and collective identities. The references made in the historic narratives indicate the strong influence of the notion of Curitiba as a "model city" in the Curitibana identity and in the formation of the historic awareness of students in the city.

Keywords: Youth. Identity. Teaching of history. 
Geyso Dongley Germinari

E-mail: geysog@gmail.com

Recebido em: 29/2/2012

Versão final recebida em: 27/9/2012

Aprovado em: 9/11/2012 